\title{
Parque Natural das Lagoas de Cufada, Guiné-Bissau. Desafios, Ameaças e Perspetivas
}

\author{
Luís Catarino \\ cE3c - Centro de Ecologia, Evolução e Alterações Ambientais. \\ Departamento de Biologia Vegetal, Faculdade de Ciências, \\ Universidade de Lisboa, Portugal
}

$\mathrm{O}$ autor dedica este trabalho à memória de Justo Nadum, homem bom que muito pugnou pela defesa da Cufada; Capitão de mar e terra e guardião da natureza.

DOI: https://doi.org/10.31492/2184-2043.RILP2018.35/pp.17-30

\begin{abstract}
Resumo
O Parque Natural das Lagoas de Cufada (PNLC) foi criado em 2000 no sul da Guiné-Bissau e tem uma área de cerca de $720 \mathrm{~km}^{2}$. As Lagoas de Cufada, Bedasse e Bionra, que dão nome ao Parque, são importantes para muitas espécies de aves migratórias, o que esteve na base da classificação como sítio Ramsar, zona húmida de importância internacional. O PNLC enfrenta ameaças e desafios relacionados com a compatibilização da conservação da natureza com os interesses das populações residentes e o desenvolvimento do país. Além de intervenções de agentes externos, algumas práticas de uso corrente pelas populações residentes têm impactes na flora e fauna do Parque. Neste sentido, um desafio importante é como promover a mudança de práticas instituídas para uma maior sustentabilidade na utilização dos recursos naturais. Um adequado planeamento e uma visão estratégica em que a conservação do ambiente seja um vetor importante são fundamentais para um desenvolvimento sustentável a longo prazo na área do PNLC.
\end{abstract}

Palavras-chave: África Ocidental; áreas protegidas; conservação da natureza; recursos naturais; zonas húmidas.

\section{Abstract}

The Parque Natural das Lagoas de Cufada (PNLC) was created in 2000 in the south of Guinea-Bissau and has an area of about $720 \mathrm{~km}^{2}$. The Cufada, Bedasse and Bionra Lagoons, which give the Park its name, are important for many species of migratory birds, which was the basis for classification as a Ramsar site, a wetland of international importance. The PNLC faces threats and challenges related with the compatibility of nature conservation with the interests of the resident populations and the development of the country. In addition to interventions by external agents, some practices commonly used by resident populations have impacts on the flora and fauna of the Park. In this sense, a major challenge is how to promote the change of established practices for greater sustainability in the use of natural resources. Adequate planning and a strategic vision in which environmental conservation is an important vector are fundamental to long-term sustainable development in the PNLC area.

Keywords: West Africa; protected areas; conservation of nature; natural resources; wetlands.

\section{Introdução}

O Parque Natural das Lagoas de Cufada (Figura 1) foi formalmente instituído pelo Decreto no 13/2000, publicado no Boletim Oficial no 49 da República da 
Guiné-Bissau (Anónimo, 2000), que igualmente formalizou os Parques de Cacheu, no litoral Norte do país e de Orango, no Arquipélago dos Bijagós.

A região hoje delimitada como Parque Natural das Lagoas de Cufada tem sido, desde há algumas dezenas de anos, considerada como área com interesse para conservação da natureza a carecer de estudo e preservação. Já Frade et al. (1946), se referiam à Lagoa de Cufada como “... um perfeito viveiro de avifauna, que convém conservar em regime de reserva especial", enquanto Ferreira (1948), num trabalho ainda de carácter eminentemente cinegético, refere, acerca da necessidade da criação da "Reserva de Cufada": "...saibamos todos nós compreender a necessidade de criar e conservar alguns recantos sagrados onde os bichos possam encontrar abrigo seguro contra as perseguições do homem".

Mais recentemente, vários autores referem a região do Parque como área a necessitar de preservação, quer pela importância para a avifauna migratória quer pela vegetação que envolve as zonas húmidas (Limoges \& Ribillard, 1990; Pessoa \& Cavaco, 1990; Sayer et al., 1992). Vários estudos faunísticos, nomeadamente em ornitologia, comprovaram também a importância das lagoas de Cufada como zona húmida de elevada importância. Poorter \& Zwarts (1984), Araújo (1994) e Araújo et al. (1998) fizeram o recenseamento das espécies de aves que frequentam estas zonas húmidas, atestando o seu interesse conservacionista nomeadamente pelo número de indivíduos e diversidade de espécies de aves.

Neste âmbito, e ainda antes da criação do Parque, a Lagoa de Cufada foi considerada uma zona húmida de importância internacional e incluída na lista de locais a proteger no âmbito da convenção de Ramsar (Scott \& Pineau, 1990). Das três lagoas existentes no Parque, a Lagoa de Cufada é a maior (Figura 2), abrigando periodicamente diversas espécies de aves aquáticas migratórias, algumas das quais consideradas de importância internacional pelo IWRB (International Waterfowl Research Bureau), nomeadamente o pelicano-branco (Pelecanus onocrotalus) e o colhereiro-africano (Platalea alba) (Araújo, 1994). Acresce que a Cufada é uma das raras lagoas da Guiné-Bissau que na época seca permanecem com água doce, circunstância que explica a ela acorrerem, nesse período, populações de numerosas espécies, incluindo diversos mamíferos.

No âmbito da Convenção de Lomé (VII FED), foi aprovado o Projeto Conservação e Utilização Racional dos Ecossistemas Frágeis, de que a criação do Parque Natural das Lagoas de Cufada foi uma componente, beneficiando do apoio científico e financeiro de Portugal (Projeto 7ACP.GUB.045). Como resultado dos estudos prévios para a criação do PNLC, efetuados entre 1996 e 2001 no âmbito deste projeto, foram realizadas comunicações e publicados trabalhos sobre esta 
área protegida em várias áreas científicas, nomeadamente flora e vegetação terrestre (Catarino, 2002, Catarino et al., 2002, 2006a, 2006b; Martins et al., 2006), ecologia da vegetação da Lagoa de Cufada (Catarino et al. 1998, 2001, 2002), fauna aracnoentomológica. (Baessa-de-Aguiar 2002; Bivar-de-Sousa \& Mendes 1999; Mendes \& Baessa-de-Aguiar, 2002), fauna de répteis e batráquios (Pinheiro, 2002), parasitologia (Rosa et al., 2002), pedologia (Milho-da-Conceição, 2001), geologia (Ramalhal, 1998) e socio-economia (Imbali et al., 1997).

Foram também elaboradas publicações e comunicações sobre o processo de criação do PNLC e as suas potencialidades e interesse conservacionista (Costa, 2000; Costa et al., 1999a, 1999b, 2001; Soares \& Silva, 2001; Vasconcelos, 2000). Nos últimos anos têm sido feitos vários estudos no PNLC, com destaque para a primatologia, com a publicação de trabalhos como Amador et al. (2015), Amaro (2011), Carvalho et al. (2013, 2015a, 2015b), Sousa (2008), e Sousa et al. (2013).

Este trabalho tem como objetivo dar a conhecer as principais características do PNLC, apresentar as ameaças e desafios à conservação da natureza nesta área protegida e discutir perspetivas para o futuro próximo.

\section{Os valores ecológicos, ambientais e atividades humanas no PNLC}

O Parque Natural das Lagoas de Cufada situa-se na Região de Quínara, no Sul da Guiné-Bissau, aproximadamente entre $11^{\circ} 34^{\prime}$ e $11^{\circ} 51^{\prime}$ Norte e entre $14^{\circ} 49^{\prime} \mathrm{e}$ $15^{\circ} 16^{\prime}$ Oeste e tem atualmente uma área de cerca de 72.000 ha. Está em estudo a possibilidade de ampliação da área do PNLC para norte do Rio Corubal (Figura 1), numa extensão adicional de cerca de 15.000 ha.

Figura 1. Localização e limites do Parque Natural das Lagoas de Cufada (mapa elaborado por APalminha).

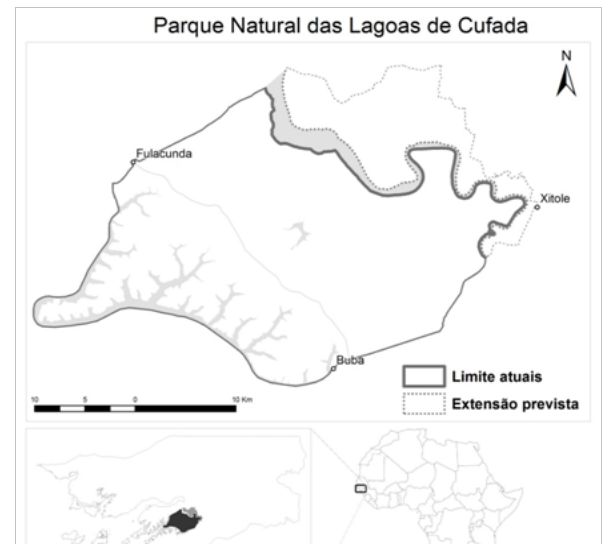


O relevo na área do Parque é pouco acentuado, com um máximo de $39 \mathrm{~m}$ de altitude havendo uma área apreciável de terras planas, algumas delas sujeitas ao efeito das marés. Os solos mais comuns são Ferralsolos pardacentos, amarelos e vermelhos. Nas zonas baixas há Gleissolos e, bordejando estes, ocorrem Plintossolos delgados sobre materiais lateríticos a pequena profundidade, ocasionalmente com afloramentos de bancada laterítica (boual). Nas zonas sob efeito das marés encontram-se Fluvissolos (Milho-da-Conceição 2001).

A vegetação do Parque é constituída principalmente por floresta densa seca, floresta aberta e savana arborizada nas zonas de solos secos, palmar de Elaeis guineensis, galerias florestais e floresta inundável em zonas de solos húmidos ou alagados durante uma parte do ano e savanas herbáceas (lalas) nas zonas baixas periodicamente alagadas na época das chuvas. Nas zonas sujeitas ao efeito das marés das margens do Rio Grande de Buba e Rio Corubal ocorrem mangais em que são dominantes Rhizophora spp. e Avicennia germinans.

A população do Parque reflecte um pouco da diversidade étnica existente na Guiné-Bissau: as etnias mais representadas são a Beafada, largamente maioritária, a que se seguem Balanta, Fula, Manjaca e Papel. Cada etnia tem as suas especificidades culturais e religiosas, que se reflectem nomeadamente nos modos de utilização dos recursos naturais.

Figura 2. Lagoa de Cufada, em fotografia aérea de 1978.

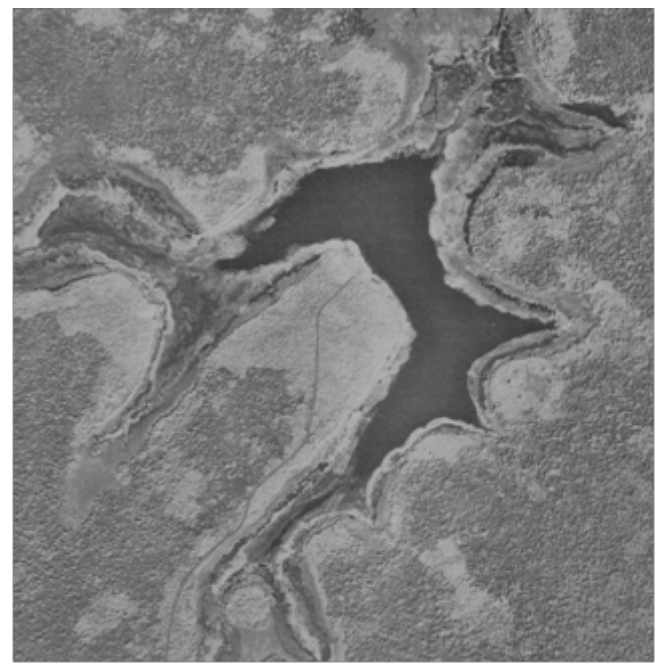

As principais actividades económicas desenvolvidas pelas populações residentes centram-se na agricultura, extracção de produtos florestais, caça, pesca, produção artesanal de artefactos e pecuária (Costa et al., 2001). A maioria da população residente retira da terra, directa ou indirectamente, o 
seu sustento, recorrendo sobretudo a métodos tradicionais de utilização dos recursos naturais. $\mathrm{O}$ arroz é a principal cultura agrícola e a base da alimentação em todas as etnias no Parque. Na zona norte, junto ao Rio Corubal há extensas zonas de bolanha onde se cultiva arroz inundado ou arroz de bolanha ao passo que no resto do Parque este cereal é cultivado em sequeiro (m 'pampam). As culturas de milho, sorgo, milheto, feijão e amendoim são igualmente feitas em sequeiro.

A extracção de produtos florestais pode ser dividida em produtos lenhosos e não lenhosos. Os principais tipos de utilizações da madeira extraída são para construção, como combustível e para fabrico de artefactos, estando a extracção de madeira para indústria interdita na área do Parque. No domínio da extracção de produtos florestais não lenhosos incluem-se o tchebém (fruto da palmeira-de-óleo, Elaeis guineensis), a extracção de mel e a recolecção de produtos florestais diversos (Figura 3). O corte de tchebém, actividade económica importante na zona do Parque, é praticado por várias etnias, com destaque para os Papel para extração de óleo de palma, importante na alimentação local. Da palmeira-de-óleo extrai-se ainda a seiva de que, por fermentação, se produz o chamado vinho-de-palma, bebida apreciada pelas etnias não muçulmanas. Vários outros produtos florestais não lenhosos são retirados pelas populações da vegetação natural, podendo agrupar-se em produtos de uso alimentar, como frutos e tubérculos, e não alimentar, nomeadamente para utilizações medicinais, religiosas ou para fabrico de artefactos.

Figura 3. Fabrico de óleo de palma, em Uaná Porto (foto LCatarino).

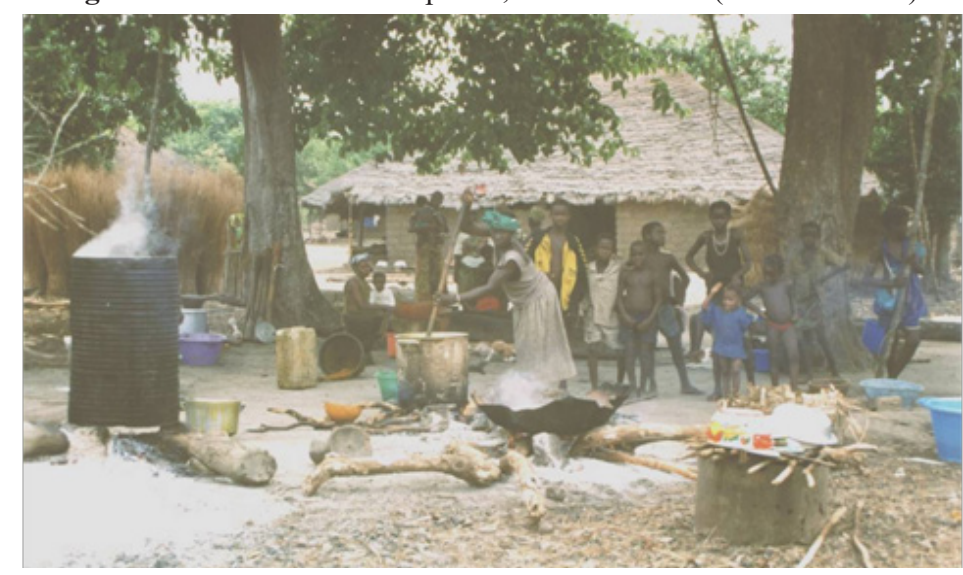

A caça é praticada no Parque sobretudo por Beafadas e Fulas, enquanto os Balantas só a praticam ocasionalmente e de forma coletiva, já que, por tradição, não são caçadores. A pesca nas lagoas é praticada por todas as etnias que possuem tabancas nas proximidades de qualquer das três lagoas, embora o maior número 
de pescadores pertença às etnias Beafada e Fula e o maior esforço de pesca seja na lagoa de Cufada (Figura 4). A actividade piscatória é também praticada no Rio Corubal e no Rio Grande de Buba.

Figura 4. Pesca na Lagoa de Cufada (foto LCatarino)

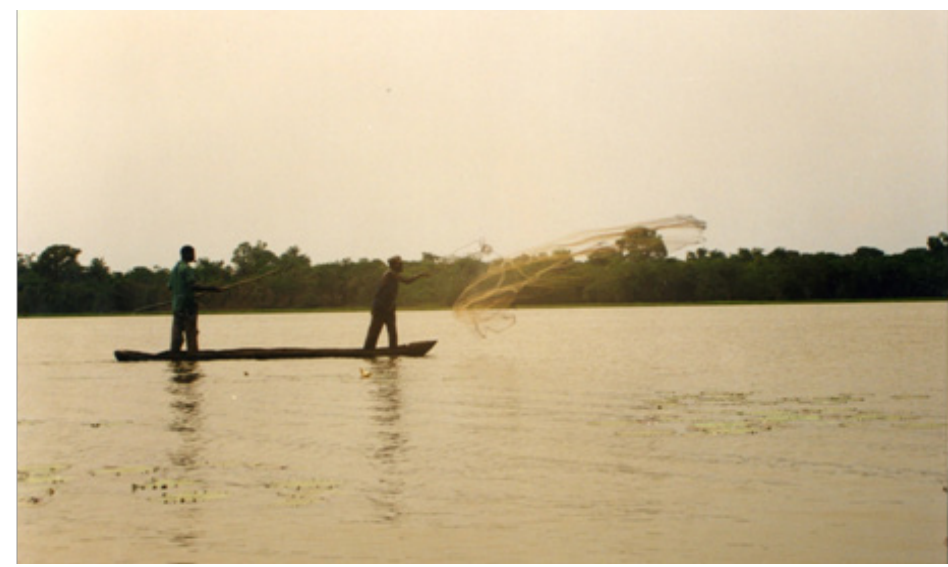

Embora em todas as tabancas haja criação de animais, a pecuária encontra-se pouco desenvolvida. A criação de gado bovino é praticada sobretudo pelos balantas, cujas tabancas se localizam maioritariamente junto ao Rio Corubal, mas o número de cabeças é diminuto. Já a criação de cabras e galinhas está difundida por todo o Parque, mas o número total de animais não parece elevado e pastam nas imediações das tabancas. Os porcos são também criados nas tabancas de etnias não muçulmanas.

Nas últimas décadas a cultura de caju tornou-se uma importante actividade económica local (Imbali et al., 1997), à semelhança do que acontece em todo o país (Catarino et al., 2013), sendo a principal fonte de receitas de muitas tabancas, possibilitando a aquisição de bens e produtos de primeira necessidade, embora acarrete derruba e queima de floresta.

\section{As lagoas de Cufada, Bedasse e Bionra}

As Lagoas que dão nome ao Parque situam-se na região Noroeste do PNLC, que faz parte da bacia hidrográfica do Rio Corubal e é caracterizada pela predominância de terras baixas, com uma altitude máxima de 27 metros. As bacias hidrográficas das três lagoas têm uma superfície total de $143,2 \mathrm{Km}^{2}$, cerca de metade correspondendo à bacia da lagoa de Cufada (Figura 5). A lala que existe em redor das lagoas e para jusante até ao Rio Corubal, permanece alagada durante vários meses no ano, havendo comunicação entre as lagoas e entre estas e o rio durante parte da estação das chuvas e o início da estação seca. Após o enchimento das lagoas o excesso de água é drenado para o Rio Corubal através do Rio de 
Ancamba e do Rio de Bionra.

As três lagoas apresentam um incremento e decréscimo sazonais de superfície e de profundidade da água bastante acentuados, com o máximo na época das chuvas e o mínimo no final da estação seca. A profundidade máxima é de cerca de 2,2 m após o fim da estação das chuvas e de 1,2 m no fim da estação seca. A água da lagoa de Cufada é macia, hipossalina, de reacção ácida e com bastante turbidez. Tem pH muito baixo e é bastante diluída, com concentrações de solutos invulgarmente baixas mesmo numa região de alta pluviosidade como a África Ocidental (Catarino et al., 2002).

Figura 5. Vista da Lagoa de Cufada em foto "olho de papagaio" (foto ASilva, IBAP).

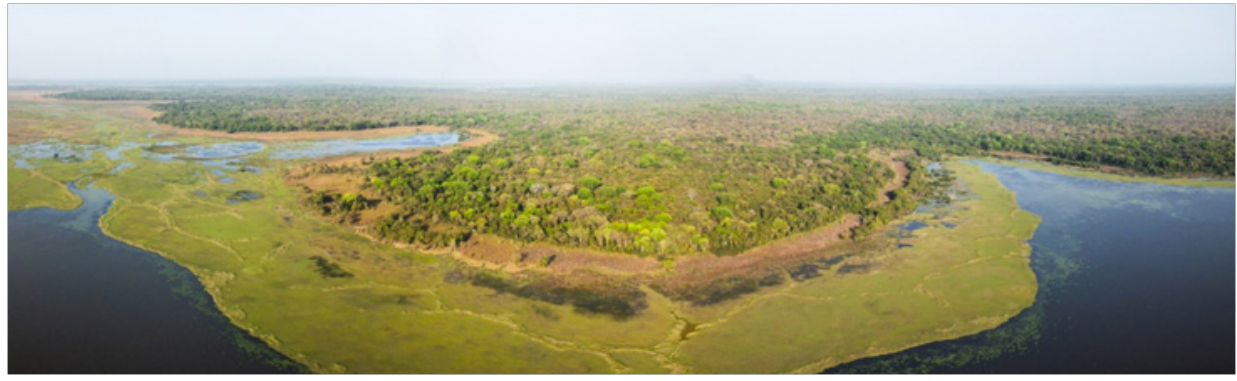

A lagoa de Cufada é a maior massa de água doce lêntica permanente na Guiné-Bissau, possuindo uma flora bastante característica, em que são dominantes os nenúfares, Nymphaea lotus e N. micrantha e o arroz-bravo, Oryza longistaminata (Figuras 6 e 8). As lagoas de Bedasse e Bionra, embora de menores dimensões, mantêm também em geral água durante a época seca e têm menor presença humana, podendo assim ser mais favoráveis à permanência de fauna selvagem.

Figura 6. Vista da Lagoa de Cufada em foto "olho de papgaio", notando-se em prmeiro plano os dois principais tipos de vegetação aquática (foto ASilva, IBAP).

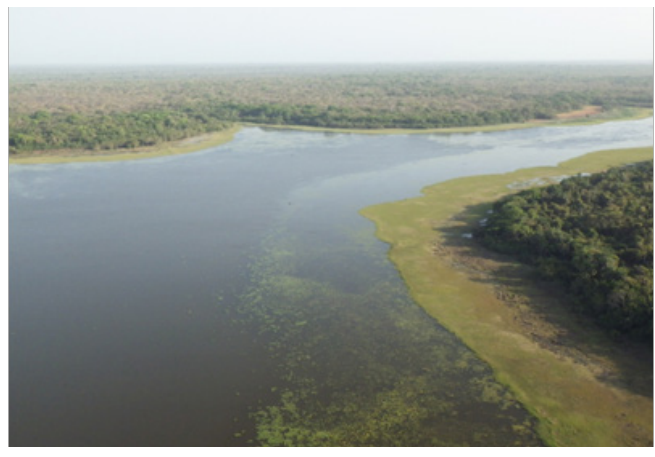

A rica avifauna migratória possibilitou a classificação da lagoa de Cufada como sítio Ramsar, conferindo-lhe o estatuto de zona húmida de importância internacional. $\mathrm{Na}$ época seca passam pela Cufada grandes quantidades de aves 
migratórias, nomeadamente pelicano (Pelecanus spp.), pato-ferrão (Plectropterus gambensis) e diversas espécies de garças (Figura 7). Está também referenciada a presença nas imediações das lagoas de numerosos outros vertebrados, como hipopótamo (Hipopotamus amphibius amphibius), manatim (Manatus senegalensis), gazela-de-lala (Kobus kob kob), gibóia (Python sebae), crocodilo (Crocodilus niloticus) e varano (Varanus varanus). Recentemente foi também confirmada a presença de elefante (Loxodontha africana) no PNLC.

Figura 7. Patos-ferrões e pelicanos, duas das espécies de aves migratórias mais abundantes na Lagoa de Cufada (foto LCatarino).

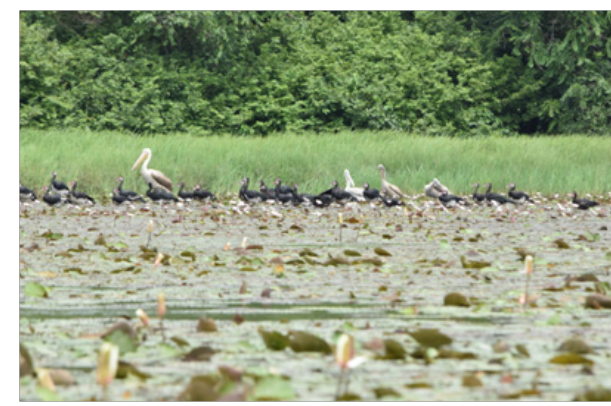

As três lagoas são importantes para as populações locais como local de pesca. A pesca tradicional é praticada durante todo o ano na lagoa de Cufada e esporadicamente nas lagoas de Bedasse e Bionra. De entre os peixes mais capturados podem referir-se bentana (Tilapia spp.), rebenta-conta (Elops lacerta), candambala (Notopterus afer), antónio-boca (Plectorhinchus macrolepis), peixe-sapato (várias espécies da família Siluridae, sub-família Clarinae) e peixe-manel.

Figura 8. Os dois principais tipos de vegetação da Lagoa de Cufada. Em primeiro plano vegetação aquática enraizada de folhas flutuantes, dominada por nenúfares (Nymphaea lotus e $N$. micrantha) e em segundo plano, à direita, vegetação aquática emergente, dominada por Oryza longistaminata (foto LCatarino).

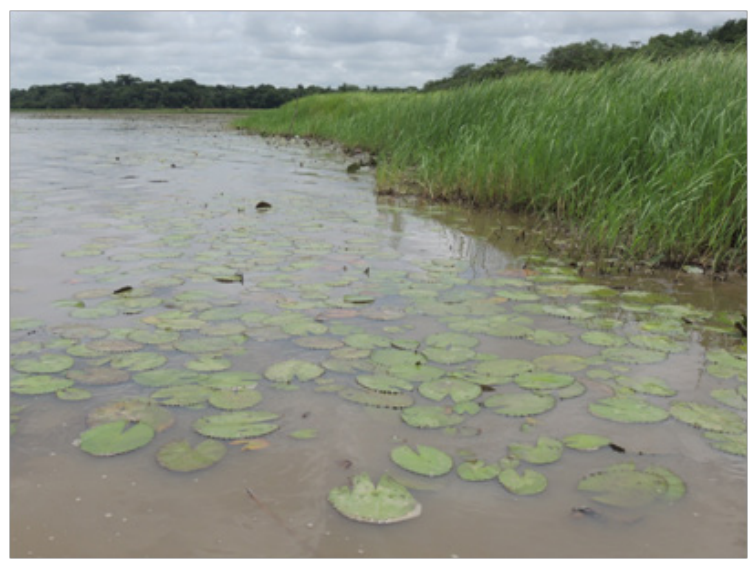




\section{Entre ameaças externas e desafios internos}

O PNLC enfrenta ameaças e desafios que em parte são comuns às restantes áreas protegidas da Guiné-Bissau, que se prendem com a compatibilização da conservação da natureza numa zona ecologicamente sensível com os interesses das populações residentes e o desenvolvimento do país. Estas dificuldades são agravadas por alguma instabilidade no quadro institucional que tem persistido ao longo dos anos no país, assim como pelo deficiente funcionamento do sistema judicial, permitindo que a legislação e os regulamentos vigentes nem sempre sejam cumpridos.

Neste contexto, o Instituto da Biodiversidade e das Áreas Protegidas da Guiné-Bissau (IBAP), instituição responsável pela conservação da natureza e da biodiversidade, que tem a tutela das áreas protegidas no país, apesar da boa implantação no terreno, tem alguma falta de capacidade de imposição de regras a nível das comunidades residentes mas sobretudo de fazer valer a conservação da natureza como vetor importante a ter em conta pelos atores externos com intervenção na área do Parque.

Após a criação desta área protegida, duas intervenções conduzidas por atores externos tiveram impactos não negligenciáveis na área do PNLC. Há cerca de uma década, a propósito da planeada construção de um porto de águas profundas no Rio Grande de Buba, foi aberto um estradão na região sul do PNLC, destruindo parte de uma das zonas de floresta mais bem preservadas do Parque (Salgado et al., 2009). Até ao presente a infraestrutura não foi construída, mas ficaram as consequências da intervenção, nomeadamente com o avanço da desflorestação no local.

Mais recentemente começou a ser construída uma central termoelétrica dentro do PNLC perto de Buba, bem como linhas de transporte de eletricidade para a instalação das quais foi derrubada uma faixa de vegetação paralela às estradas existentes. Sem questionar a pertinência da construção da infraestrutura ou da tecnologia utilizada, resta a dúvida se a localização dentro do PNLC será a melhor opção, assim como sobre se o impacte da construção das linhas de transporte de energia não poderia ser minorado.

Sendo certo que a Guiné-Bissau necessita de desenvolvimento e de reforçar as suas infraestruturas, um planeamento adequado e uma visão estratégica em que a conservação do ambiente seja uma aposta importante são fundamentais para um desenvolvimento sustentável a longo prazo.

Dentro do PNLC, a relação com as populações residentes e com os "donos do chão" é um desafio sempre presente, requerendo um trabalho contínuo de persistência e de conquista das mentalidades, nem sempre fácil e com resultados incertos. É necessário fazer sentir às populações residentes que a longo prazo a 
conservação da natureza e a gestão sustentável dos recursos naturais são a melhor forma de garantir o futuro.

Por outro lado, algumas práticas tradicionais de uso corrente, como as queimadas agrícolas, a agricultura itinerante e o abate de animais selvagens, têm impactes na flora e fauna do Parque. Um desafio importante é como promover a mudança de práticas há muito instituídas, no sentido de conseguir uma maior sustentabilidade na utilização dos recursos naturais.

Dado que a imposição externa de práticas não é em geral bem sucedida, uma forma viável de implementar mudanças de práticas pode ser a disponibilização de alternativas menos impactantes e de preferência vantajosas para as populações residentes.

Como em todo o país, os pomares de cajueiros têm aumentado de área no PNLC nas últimas décadas, em particular junto às povoações. Sendo esta tendência bastante difícil de contrariar, uma forma de lidar com o assunto pode ser o estabelecimento de acordos com as populações residentes sobre as áreas em que esta cultura se pode praticar e que se devem refletir no zonamento do Parque.

Um fenómeno que parece estar em expansão é a cedência de terrenos por residentes no PNLC, que têm direito ao uso do chão, a forasteiros que não têm, nomeadamente perto dos pólos urbanos de Buba e Fulacunda. Nestes terrenos são em geral instalados cajuais pelo que esta prática necessita de ser devidamente acompanhada e dissuadida.

\section{Discussão}

Os O Parque Natural das Lagoas de Cufada alberga ecossistemas únicos na Guiné-Bissau e a nível sub-regional cuja conservação está a cargo do IBAP (IBAP 2007). A possibilidade de aumento da área do PNLC para norte do Rio Corubal, irá aumentar a superfície desta área protegida. Ao incluir um troço da parte jusante do Rio Corubal, e algumas zonas de vegetação florestal ainda bem preservadas este alargamento do PNLC permitirá englobar uma maior diversidade de ecossistemas nesta área protegida.

Uma gestão sustentável e participativa dos recursos naturais no PNLC é fundamental para preservação das comunidades animais e vegetais e para o bem-estar das populações residentes. Assim, uma questão relevante é como conciliar a conservação da natureza com a melhoria do bem-estar das populações residentes sem que no entanto o interior do Parque atraia novas populações.

Nas áreas protegidas com população residente, como é o caso do PNLC, a conservação da natureza tem de ser feita com a colaboração dos residentes, incluindo na mudança de práticas com impactes negativos. No entanto, para que tal 
aconteça é necessário fornecer alternativas viáveis e de preferência vantajosas, que possam ser adotadas e apropriadas pelos residentes.

Algumas ações que podem ser implementadas com possibilidades de sucesso podem ser por exemplo o fomento da extração e a valorização de produtos florestais não lenhosos, a intensificação sustentável da agricultura nas zonas de desenvolvimento comunitário e a promoção do ecoturismo.

A extração e valorização de produtos florestais não lenhosos está ainda pouco desenvolvida no PNLC. Alguns produtos, como a farroba, o veludo ou o mel têm potencial para maior valorização e podem ser um bom complemento do rendimento das famílias.

Por outro lado, sendo a agricultura a base do sustento das famílias residentes, uma intensificação sustentável da agricultura nas zonas de desenvolvimento comunitário, se acompanhada de um zonamento adequado, pode contribuir para o aumento do bem estar das famílias sem aumentar a pressão sobre a vegetação natural. Algumas técnicas de melhoramento da fertilidade dos solos já experimentadas em situações semelhantes, como a utilização de leguminosas fixadoras de azoto, assim como os sistemas agroflorestais, podem ser também aplicadas no PNLC.

Em relação ao ecoturismo, embora exista potencial no PNLC, além das infraestruturas necessárias estarem pouco desenvolvidas, é uma atividade que depende bastante de fatores externos, pelo que o seu contributo para a economia na zona do Parque deve continuar a ser diminuto nos próximos tempos.

Um importante instrumento de gestão numa área protegida é o Plano de Ordenamento e Gestão e em particular a componente de zonamento, que permite nomeadamente delimitar áreas de proteção, em que as restrições de utilização são fortes, e áreas de utilização comunitária, nas quais as populações residentes praticam atividades para prover o próprio sustento. Regras de utilização claras e discutidas com a população residente e uma delimitação aceite e bem conhecida do zonamento são fundamentais para permitir uma boa gestão do território numa área protegida.

A legislação vigente e os instrumentos de gestão de uma área protegida como o PNLC e em particular o Plano de Ordenamento e Gestão devem ser a base da atuação dentro da área protegida dos diferentes atores internos e externos. A tomada de decisões casuísticas e pouco ponderadas sem a consulta aos principais atores interessados e sem atender às especificidades próprias de uma zona de interesse conservacionista deve ser evitada quando se pretende prosseguir uma estratégia de desenvolvimento durável. 


\section{Agradecimentos}

O autor deseja agradecer a Agostinho Palminha a realização do mapa apresentado na Figura 1 e a António da Silva a cedência das fotografias apresentadas nas Figuras 5 e 6, assim como a Aissa Regalla, Coordenadora do Departamento de Monitoria e Conservação da Biodiversidade do IBAP e a Joãozinho Mané, Diretor do PNLC pela leitura da versão inicial do manuscrito e sugestões formuladas.

\section{Referências}

Amador, R., Casanova, C., \& Lee, P. (2015). Ethnicity and Perceptions of Bushmeat hunting inside Lagoas de Cufada Natural Park (LCNP), Guinea-Bissau. J. Primatol 3: 121.

Amaro, A. P. (2011). Constituição da Baseline para Projectos de Carbono no Parque da Cufada no Âmbito do Mecanismo REDD+. Dissertação Mestrado, Faculdade de Ciências e Tecnologia, Universidade Nova de Lisboa.

Anónimo. (2000). Decreto nº 13/2000 - Criação dos Parques Naturais das Lagoas de Cufada, Tarrafe de Cacheu e de Orango. Boletim Oficial da República da Guiné-Bissau, no 49.

Araújo, A. (1994). A importância ornitológica da região da Cufada na Guiné-Bissau. Série de Biologia e Conservação da Natureza, Lisboa, ICN, 13: 1-71.

Araújo. A. (1995). Na Lagoa da Cufada, reino das aves. Volta ao Mundo, 46: 46-50.

Araújo. A., Catry, P., Cruz, C., Pinheiro, A., Poças, M., Nadum, J., Armelin, M., \& Pereira, J. R. (1998). Report on the ornitological expedition to the Cufada Natural Park (Guinea-Bissau) in 1995. Relatório não publicado 40 p. Lisboa, ICN.

Baessa-de-Aguiar, O. (2002). Contribuição para o estudo das aranhas (Aracnida: Araneae) do Parque Natural das Lagoas de Cufada (Guiné-Bissau). Garcia de Orta - Sér. Zool. 24 (1/2): 113-117.

Bivar-de-Sousa, A., \& Mendes, L. F. (1999). Nota preliminar sobre a fauna de Lepidópteros diurnos (Papilionoideae e Hesperioideae) do Parque Natural das Lagoas de Cufada (Guiné-Bissau). Bol. Soc. Port. Entomologia, Supl. 6: 33-46.

Carvalho, J. S. (2014). Conservation status of the endangered chimpanzee (Pan troglodytes verus) in Lagoas de Cufada Natural Park (Republic of Guinea-Bissau). Dissertação Doutoramento, Universidade de Lisboa.

Carvalho, J. S., Marques, T. A., \& Vicente, L. (2013). Population status of Pan troglodytes verus in Lagoas de Cufada Natural Park, Guinea-Bissau". PloS One, 8(8): e71527.

Carvalho, J.S., Meyer, C. F. J., Vicente, L., \& Marques, T. A. (2015b). Where to nest? Ecological determinants of chimpanzee nest abundance and distribution at the habitat and tree species scale. American Journal of Primatology, 77: 186-199.

Carvalho, J.S., Vicente, L., Marques, T. A. (2015a). Chimpanzee (Pan troglodytes verus) diet composition and food availability in a human-modified landscape at Lagoas de Cufada Natural Park, Guinea-Bissau. Int J Primatol 36(4): 802-822. 
Catarino, L., Martins, E. S., Diniz, M. A., \& Pinto-Basto, M. F. (2006a). Check-List da flora vascular do Parque Natural das Lagoas de Cufada (Guiné-Bissau). Garcia de Orta, Sér. Bot., 17(12): 97-141.

Catarino, L., Martins, E. S., \& Diniz, M. A. (2006b). Tipos fisionómicos de vegetação arbórea do Parque Natural das Lagoas de Cufada (Guiné-Bissau). Garcia de Orta, Sér. Bot., 17(1-2): 69-76.

Catarino, L. (2002). Flora e Vegetação do Parque Natural das Lagoas de Cufada (Guiné-Bissau). Lisboa, IICT.

Catarino, L., Martins, E. S., \& Diniz, M. A. (1998). The Aquatic Plant Communities in Cufada Lagoons (Guinea-Bissau). Proc. 10th International Symposium on Aquatic Weeds, Lisboa, 39-42.

Catarino, L., Duarte, M. C., \& Moreira, I. (2001). Vegetação da Lagoa de Cufada (Guiné-Bissau): uma aproximação fitossociológica. Quercetea 3: 127-140.

Catarino, L., Menezes, Y., \& Sardinha, R. (2015). Cashew culture in Guinea-Bissau - risks and challenges of the success of a cash crop. Scientia Agricola 72(5): 459-467.

Catarino, L., Martins, E. S., \& Diniz, M. A. (2002). Vegetation structure and ecology of the Cufada Lagoon (Guinea-Bissau). Afr. J. Ecol. 40(3): 252-259.

Costa, R. (2000). Lagoas de Cufada - Um parque natural na Guiné-Bissau. Notícias Magazine, $n^{0}$ 442: $120-130$.

Costa, R., Mendes, L. F., Martins, E. S., Milho-da-Conceição, F., Ramalhal, F. J. S., \& Catarino, L. (1999a). Estudos Preliminares e Plano de Ordenamento do Parque Natural das Lagoas de Cufada. Livro de Resumos do $4^{\circ}$ Congresso Nacional de Áreas Protegidas, Lisboa, 113.

Costa, R., Réffega, A., Diniz, M. A., \& Crawford-Cabral, J. (1999b). Parque Natural das Lagoas de Cufada: Orígem, Orgânica e Evolução do Projecto. Livro de Resumos do $4^{\circ}$ Congresso Nacional de Áreas Protegidas, Lisboa, 112.

Costa, R., Djaló, M. A., Catarino, L., Mendes, L. F., Martins, E. S., Diniz, M. A., Conceição, F. M., Ramalhal, F. J. S., \& Nunes, M. C. (2001). Parque Natural das Lagoas de Cufada (Guiné-Bissau). Livro de Resumos do $2^{\circ}$ Congresso Nacional de Conservação da Natureza, Lisboa, 36.

Ferreira, J. A. (1948). Fauna da reserva de Cufada. Boletim Cultural da Guiné Portuguesa, 3(11): 739-758.

Frade, F., Bacelar, B. \& Gonçalves, B. (1946). Relatório da Missão Zoológica e contribuições para o conhecimento da fauna da Guiné Portuguesa. Anais da Junta de Investigações Coloniais, 1: 261-415.

IBAP (2007). Estratégia nacional para as áreas protegidas e a conservação da biodiversidade na Guiné-Bissau 2007-2011. Bissau, IBAP.

Imbali, F., Silva, A. O., \& Incuca, J. (1997). Estudo do impacto sócio-económico da criação do Parque Natural das Lagoas de Cufada sobre as populações residentes. Relatório fotocopiado. Bissau, INEP.

Limoges, B., \& Robillard, M.J. (1990). Proposition d'un Réseau d'aires Protegées en Guinée-Bissau (zone continentale). Étude financée par la CACI et l'UICN. Relatório fotocopiado. Bissau, MDRA-DGFSC. 
Martins, E. S., Catarino, L., \& Diniz, M. A. (2006). Taxa novos ou pouco conhecidos da flora vascular da Guiné-Bissau colhidos no Parque Natural das Lagoas de Cufada. Garcia de Orta - Sér. Bot. 17(1-2): 77-82.

Mendes, L. F., \& Baessa-de-Aguiar, O. (2002). Fauna aracnoentomológica do Parque Natural das Lagoas de Cufada (Guiné-Bissau). Análise preliminar dos dados obtidos pela primeira missão do Centro de Zoologia. Garcia de Orta - Sér. Zool. 24(1/2): 51-59.

Milho-da-Conceição, F. (2001). Informação preliminar acerca dos solos do Parque Natural das Lagoas de Cufada na Guiné-Bissau. Rev. Ciências Agrárias 24(3-4): 13-21.

Pessoa, F., \& Cavaco, J. (1990). Projecto do Parque Natural da Cufada. Bissau, Direcção-Geral de Florestas e Caça, Bissau - Lisboa, Serviço Nacional de Parques, Reservas e Conservação da Natureza. Relatório fotocopiado.

Pinheiro, M. (2002). Répteis e batráquios do Parque Natural das Lagoas de Cufada (Guiné-Bissau) e a problemática da sua conservação. Livro de Resumos, VII Congresso Luso-Espanhol de Herpetologia, Évora, 71.

Poorter, E., \& Zwarts, L. (1984). Résultats d'une première mission ornito-écologique de l'UICN/WWF en Guinée-Bissau. Zeist, Fondation Néerlandaise pour la Proteccion Internationale des Oiseaux. Relatório fotocopiado.

Ramalhal, F. (1998). Relatório de progresso, componente Geologia-Hidrogeologia. Lisboa, Centro de Geologia do IICT. Relatório fotocopiado.

Rosa, F., Crespo, M. V., \& Mendes, L. F. (2002). Contribuição para o conhecimento da fauna do Parque Natural das Lagoas de Cufada. Diversidade parasitária em Cercopithecus mona Campbelli (Mammalia; Primates). Garcia de Orta - Sér. Zool. 24(1/2): 171-174.

Salgado, A., Fedi, F., \& Leitão, F. (2009). Relatório preliminar do processo de construção do Porto de Buba e seus impactos. Bissau, IBAP.

Scott, D. A., \& Pineau, O. (1990). Promotion of Ramsar Convention and survey of Lagoa de Cufada, Guinea-Bissau. Bissau, UICN. Relatório de Missão.

Soares, S., \& Silva, J. P. (2001). Guiné-Bissau - Parque das Lagoas de Cufada: o esplendor da natureza africana. Cooperação, 1: 23-26.

Sousa, J. (2008). Densidade de Pan troglodytes verus (Chimpanzé da África Ocidental) no Parque Natural das Lagoas de Cufada, República da Guiné-Bissau. Dissertação de Mestrado, Faculdade de Ciências Sociais e Humanas, Universidade Nova de Lisboa.

Sousa, J., Casanova, C., Barata, A. V. \& Sousa, C. (2013). The effect of canopy closure on chimpanzee nest abundance in Lagoas de Cufada National Park, Guinea-Bissau. Primates 55, (2): 283-292.

Vasconcelos, H. (2000). Portugal-Guiné criam parque natural. Diário de Notícias, 25 de Janeiro de 2000: 22 .

Data receção: 01/08/2017

Data aprovação: 13/03/2018 